[NOTES AND DISCUSSION]

\title{
THE MAR 'AS' CONSTRUCTION IN ULSTER IRISH AND ITS THEORETICAL IMPLICATIONS
}

\author{
DÓNALl P. Ó BAOILl and HideKI MAKI \\ Queen's University Belfast and Gifu University*
}

Keywords: as, chain, COMP alternation, left periphery, Ulster Irish

\section{Introduction}

Little study has been done on the properties of the mar 'as' construction in Modern Ulster Irish (Irish, hereafter), as in (1). ${ }^{1,2,3}$

* An earlier version of this paper was presented at the 136th Meeting of the Linguistic Society of Japan held at Gakushuin University on June 21, 2008. We would like to thank the audience at the meeting, as well as the following people: Ronald Craig, Jessica Dunton, Roger Martin, Chie Nakamura, Fumikazu Niinuma, and three anonymous EL reviewers for their helpful comments. Our thanks also go to the following native speakers from the eastern borders of Gweedore parish in North West Donegal with whom the examples have been checked: Donnchadh Mac Fhionnaile, Seán Mac Giolla Chóill, Bríd Bean Mhic Íomhair, Anna Ní Bhaoill, Máire Nic Giolla Chóill, Pádraig Ó Briain, Pádraig Ó Dúgáin (Éamann), Bríd Bean Uí Ghallchóir, and Méabha Bean Uí Phíopalaigh. All errors are our own. Research by the second author was supported in part by Japan Society for the Promotion of Science Grant \#s 18520303 and 21520397 to Gifu University.

1 In this paper, in order to avoid unnecessary confusion, we only use data from the U1ster variety, one of the three main varieties of Irish: Ulster, Connacht, and Munster.

${ }^{2}$ We are indebted to the following nine informants for the Irish data discussed in this paper: Donnchadh Mac Fhionnaile, Seán Mac Giolla Chóill, Bríd Bean Mhic Íomhair, Anna Ní Bhaoill, Máire Nic Giolla Chóill, Pádraig Ó Briain, Pádraig Ó Dúgáin (Éamann), Bríd Bean Uí Ghallchóir, and Méabha Bean Uí Phíopalaigh. They are all from the North West area of Co Donegal and native speakers of this variety of Ulster Irish. They are all $60+$ now, and their daily language is Irish. They are bilingual but their command of Irish is superior to their command of English. These people spoke no English until they went to school at age $4 / 5$ and then only for one half hour a day at school. One of the co-authors of this paper is also a native speaker of this variety of Ulster Irish.

${ }^{3}$ One of the reviewers asked how the data in this paper were collected. We created minimal pairs, and showed or read (as appropriate) each pair to the informants. This has been a standard method to have judgments on data in theoretical linguistics, including 
(1) Is duine deas í, mar atá a fhios agat. COP person nice her as aL+is its knowledge at-you

'She is a nice person, as you know.'

In (1), mar 'as' in the adjunct clause mar atá a fhios agat 'as you know' functions exactly like as in the same construction in English.

In this paper, we investigate the chain properties of the construction, and show that it only allows the chain patterns headed by the direct relative marker $a L .4,5$ Then, we argue that this fact suggests (i) that there should be an agreement relationship between the head of the chain pattern and the element that the chain pattern is dependent on, and (ii) that given (i), there should exist an independent head above $\mathrm{C}$.

The organization of this paper is as follows. Section 2 provides the properties of the complementizers in Irish and the types of $\mathrm{A}^{\prime}$-chains thus far observed as a background to the subsequent sections. Section 3 presents the data with the mar 'as' construction. Section 4 discusses the implications of the findings. Finally, Section 5 concludes the paper.

\section{Background}

Irish has three types of complementizers: the [-Q] marker, the direct relative marker, and the indirect relative marker. The [-Q] marker is realized as either go (non-past) or gur (past), and this behaves in the same fashion as English [-Q] COMP that. The direct and indirect relative markers ap-

generative grammar. We did not use magnitude estimation, so that we did not make a formal questionnaire with test sentences and fillers. We directly asked our informants if there would be a difference in grammaticality between the sentences constituting a minimal pair. Therefore, we only had judgments such as (i).

(i) a. Yes, there is a difference in grammaticality between the two sentences.

b. No, there is no difference in grammaticality between the two sentences.

(Therefore, if yes, one of the sentences is grammatical, and the other is ungrammatical, and if no, both sentences are grammatical or ungrammatical.)

$4 a L$ in (1), a symbol originally used in McCloskey (1979), is a complementizer which indicates a direct relative marker. We will review the nature of this and other complementizers in Irish in Section 2.

${ }^{5}$ In this paper, for ease of exposition, we use two terms chain and chain pattern in different ways, especially in describing the first element of a given chain and chain pattern. We say that the head of a chain is an XP, such as what in (what, $t$ ), where both what and $t$ are XP elements, and that the head of a chain pattern is an $\mathrm{X}^{0}$, such as $a L$ in $(\mathrm{aL}, t)$, where $a L$ is a complementizer, and thus, is an $\mathrm{X}^{0}$ element, and $t$ is an XP element. We also say that the first element in a chain heads the chain, and that the first element in a chain pattern heads the chain pattern. 
pear in relative clauses and $w h$-interrogatives, among others. ${ }^{6}$ The basic form of the two markers is $a$, but the direct relative marker induces Lenition and the indirect relative marker Eclipsis/Nasalization on a following element. Therefore, McCloskey (1979) proposes to use $a L$ for the former, and $a N$ for the latter. The direct relative marker is realized as $a$ (nonpast and past), and the indirect relative marker as either $a$ (non-past) or ar (past). ${ }^{7}$ In this paper, following McCloskey (1979), we use the symbols $a L$ and $a N$ for the direct relative marker and the indirect relative marker, respectively.

McCloskey (2002) shows that $\mathrm{A}^{\prime}$-chains in Irish headed by an argument wh-phrase such as cad é 'what' allow five chain patterns (aL, aL, $t),(\mathrm{aN}$, $\mathrm{aL}, t),(\mathrm{aL}, \mathrm{aN}, \mathrm{it}),(\mathrm{aN}$, that, it), and (aN, $\mathrm{aN}, \mathrm{it})$, as shown in (2)-(6), where the meaning of (2)-(5) is the same.

(2) $(\mathrm{aL}, \mathrm{aL}, t)$

Cad é a chreideann tú a cheannaigh Seán $t$ ?

what aL believe you aL bought John

'What do you believe [that John bought $t$ ]?'

(3) (aN, that, it)

Cad é a gcreideann tú gur cheannaigh Seán é?

what aN believe you that bought John it

(4) (aN, aN, it)

Cad é a gcreideann tú ar cheannaigh Seán é? what aN believe you aN bought John it

(5) $(\mathrm{aL}, \mathrm{aN}, \mathrm{it})$

Cad é a chreideann tú ar cheannaigh Seán é? what aL believe you aN bought John it

(6) $(\mathrm{aN}, \mathrm{aL}, t)^{8}$

Cad é a raibh súil agat a cheannófá $t$ ?

what aN was hope at-you aL buy (COND)

'What did you hope [that you would buy $t$ ]?'

6 See McCloskey (1979) and Chung and McCloskey (1987), among others.

7 Note that the indirect relative marker in the past form, whose default form is ar, is realized as $a$ in front of a handful of irregular verbs such as bi 'to be,' déan 'to do,' and feic 'to see.'

${ }^{8}$ Maki and Ó Baoill (2007) point out that the chain pattern (aN, aL, $t$ ) is allowed only in certain constructions, such as those with psych-nouns (súil 'hope' in (6), for example, in combination with prepositional verbal phrases). Therefore, if the matrix predicate is replaced by (a) gcreideann '(aN) believe,' (6) becomes ungrammatical, as shown in (i). 
Furthermore, A'-chains headed by the reason adverbial wh-phrase cén fáth 'why' allow two chain patterns (aL, aN) (McCloskey (2002)) and (aN, aN) (McCloskey (1985)), as shown in (7) and (8). ${ }^{9} \quad$ Note that in each of the examples in (7) and (8), the adjunct wh-phrase only modifies the predicate in the embedded clause.

$(\mathrm{aL}, \mathrm{aN})$

a. Cén fáth do bharúil a dúirt Pól a ndearna sé é? why in-your opinion aL said Paul aN did he it 'Why in your opinion did Paul say [that he did it $t$ ]?'

b. Cén fáth do bharúil a chreid Pól a ndearna sé é? why in-your opinion aL believed Paul aN did he it 'Why in your opinion did Paul believe [that he did it $t]$ ?' $(\mathrm{aN}, \mathrm{aN})$

a. Cén fáth do bharúil ar dhúirt Pól a ndearna sé é? why in-your opinion aN said Paul aN did he it 'Why in your opinion did Paul say [that he did it $t$ ]?'

(i) $*(\mathrm{aN}, \mathrm{aL}, t)$

*Cad é a gcreideann tú a cheannaigh Seán $t$ ? what aN believe you aL bought John 'What do you believe [that John bought $t$ ]?'

However, for reasons still unknown, (6) with (a) gcreideann '( $\mathrm{aN}$ ) believe' becomes grammatical, if it is embedded in a full sentence. See Maki and Ó Baoill (2007) for the relevant data.

${ }^{9}$ Note that $\mathrm{A}^{\mathrm{A}}$-chains headed by the reason adverbial wh-phrase cén fáth 'why' do not allow chain patterns that end with a resumptive pronoun, as shown in (i) and (ii), where the adjunct $w h$-phrase only modifies the predicate in the embedded clause.

(i) $\quad *(\mathrm{aL}, \mathrm{aN}, \mathrm{it})$

a. *Cén fáth do bharúil a dúirt Pól a ndearna sé é é? why in-your opinion aL said Paul aN did he it it 'Why in your opinion did Paul say [that he did it $t$ ]?'

b. *Cén fáth do bharúil a chreid Pól a ndearna sé é é? why in-your opinion aL believed Paul aN did he it it 'Why in your opinion did Paul believe [that he did it $t$ ]?'

(ii) $\quad *(\mathrm{aN}, \mathrm{aN}, \mathrm{it})$

a. *Cén fáth do bharúil ar dhúirt Pól a ndearna sé é é? why in-your opinion aN said Paul aN did he it it 'Why in your opinion did Paul say [that he did it $t$ ]?'

b. *Cén fáth do bharúil ar chreid Pól a ndearna sé é é? why in-your opinion aN believed Paul aN did he it it 'Why in your opinion did Paul believe [that he did it $t$ ]?' 
b. Cén fáth do bharúil ar chreid Pól a ndearna sé é? why in-your opinion aN believed Paul aN did he it

'Why in your opinion did Paul believe [that he did it $t]$ ?'

McCloskey (2002) provides an analysis of the chain patterns in (3)-(8) by proposing (9).

(9) a. C whose specifier is filled by Move is realized as $a L$.

b. C whose specifier is filled by Merge is realized as $a N$.

c. C whose specifier is not filled is realized as go/gur.

McCloskey assumes that the SPEC of $a L$ contains a null resumptive pronoun as a result of movement, that in the SPEC of $a N$, there is a basegenerated null resumptive pronoun, and that in the SPEC of go/gur, there is no null resumptive pronoun. ${ }^{10}$ To summarize, the direct relative marker $a L$ appears when the example involves movement, and the indirect relative marker $a N$ appears when the example involves no movement.

\section{Data with the Mar 'As' Construction}

With the background established, let us consider the chain properties of the mar 'as' construction. Let us first consider the cases which have a chain pattern with two members. As shown in (1), reproduced in (10), the

10 McCloskey (2002) assumes that what moves in wh-interrogatives such as (6), reproduced as (i), is a null resumptive pronoun, based on $w$ h-interrogatives with a different type of chain pattern such as (ii).

(i) $(\mathrm{aN}, \mathrm{aL}, t)$

Cad é a raibh súil agat a cheannófá $t$ ?

what aN was hope at-you aL buy (COND)

'What did you hope [that you would buy $t$ ]?'

(ii) (aL, aN, it)

Cad é a chreideann tú ar cheannaigh Seán *(é)?

what aL believe you aN bought John it

'What do you believe [that John bought $t$ ]?'

(ii) shows that the second COMP $a N$ must bind a resumptive pronoun $e$ 'it.' With this in mind, let us consider the example in (i), where the first COMP is $a N$. If what moves in $w h$-interrogatives in Irish is a null wh-operator, the SPEC of the second COMP $a L$ in (i) would have such a null $w h$-operator, so that the first COMP $a N$ would not be able to bind any (resumptive) pronoun, which would incorrectly lead to the ungrammaticality of (i). Therefore, McCloskey (2002) proposes that what moves in wh-interrogatives in Irish is actually a null resumptive pronoun. Given this, the first COMP in (i) can bind the null resumptive pronoun moved to the SPEC of the second COMP. In this paper, following McCloskey (2002), we assume that what moves/merges to the SPEC of a COMP is a null resumptive pronoun. 
mar 'as' construction allows the chain pattern $(\mathrm{aL}, t) .{ }^{11}$

(10) $(\mathrm{aL}, t)$

Is duine deas í, mar atá a fhios agat $t$.

COP person nice her as $a \mathrm{~L}+$ is its knowledge at-you

'She is a nice person, as you know.'

However, the construction does not allow the chain pattern (aN, it), as shown in (11).

(11) $*(\mathrm{aN}, \mathrm{it})$

* Is duine deas í, mar a bhfuil a fhios agat é.

COP person nice her as aN is its knowledge at-you it

'She is a nice person, as you know it.'

Let us then consider the cases that have a chain pattern with three members and a chain pattern with two explicit members along with an implicit third member. We saw above the chain patterns with three members in whinterrogatives headed by argument and adjunct wh-phrases, and found that seven patterns were possible. In the following, we will examine if the corresponding seven patterns will be allowed in the mar 'as' construction. The examples are shown in (12)-(18), and presented in the order of the chain patterns shown in (2)-(8). The intended interpretation of (12)-(18) is that mar 'as' is connected to the corresponding element in the embedded clause, which is either $t$ or $e$ in (12)-(16), and the null resumptive pronoun (which is not overtly represented) in (17) and (18).

(12) $\quad(\mathrm{aL}, \mathrm{aL}, t)$

Is duine deas í, mar a bheifeá ag súil a

COP person nice her as aL would-be at expectation aL chreidfeadh daoine $t$.

would-believe people

11 In Irish, the example in (10), reproduced as (i), has actually two interpretations, as shown in (ii). All the informants we consulted shared this judgment.

(i) $(\mathrm{aL}, t)$

Is duine deas í, mar atá a fhios agat $t$.

COP person nice her as aL+is its knowledge at-you

'She is a nice person, as you know.'

(ii) a. the interpretation in which the content of the trace in the clause headed by mar 'as' corresponds to the matrix clause as a whole, that is, [(the fact that) she is a nice person].

b. the interpretation in which the content of the trace in the clause headed by mar 'as' corresponds to part of the matrix clause, such as $i$ 'her.'

In this paper, we only deal with the data with the interpretation in (iia) due to space limitations. 
'She is a nice person, [as you would expect [that people would believe $t]$.'

(13) $*($ aN, that, it)

* Is duine deas í, mar a mbeifeá ag súil go

COP person nice her as aN would-be at expectation that gcreidfeadh daoine é.

would-believe people it

(14) $*(\mathrm{aN}, \mathrm{aN}, \mathrm{it})$

* Is duine deas í, mar a mbeifeá ag súil a

COP person nice her as aN would-be at expectation aN gcreidfeadh daoine é.

would-believe people it

(15) $*(\mathrm{aL}, \mathrm{aN}, \mathrm{it})$

* Is duine deas í, mar a bheifeá ag súil a

COP person nice her as aL would-be at expectation aN gcreidfeadh Daoine é.

would-believe people it

(16) $*(\mathrm{aN}, \mathrm{aL}, t)$

* Is duine deas í, mar a mbeifeá ag súil a

COP person nice her as aN would-be at expectation aL chreidfeadh daoine $t$.

would-believe people

(17) $*(\mathrm{aL}, \mathrm{aN})$

* Is duine deas í, mar a bheifeá ag súil a

COP person nice her as aL would-be at expectation aN gcreidfeadh daoine.

would-believe people

(18) $*(\mathrm{aN}, \mathrm{aN})$

* Is duine deas í, mar a mbeifeá ag súil a

COP person nice her as aN would-be at expectation aN gcreidfeadh daoine.

would-believe people

As shown above, the mar 'as' construction only allows one type of chain pattern $(\mathrm{aL}, \mathrm{aL}, t)$ in (12) and disallows all the other patterns shown in (13)-(18).

Summarizing, the mar 'as' construction only allows the chain patterns in (19).

(19) a. (aL, $t)$

b. $(\mathrm{aL}, \mathrm{aL}, t)$ 


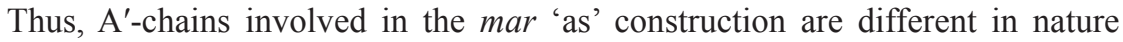
not only from $\mathrm{A}^{\prime}$-chains headed by the argument wh-phrase such as cad $e$ 'what,' but also from A'-chains headed by the reason adverbial wh-phrase cén fáth 'why.' This indicates that the null resumptive pronoun involved in the mar 'as' construction is different from the ones corresponding to the argument wh-phrase such as cad é 'what' and the reason adverbial wh-phrase cén fáth 'why.'

\section{Implications}

Let us consider what the observed facts suggest. We will show below that they suggest two linguistically significant points. First, the descriptive generalization about the mar 'as' construction is that no chain pattern headed by $a N$ is allowed for the construction. As far as wh-interrogatives and relative clauses are concerned, it has been assumed that chain patterns headed by $a L$ and those headed by $a N$ are interchangeable, as shown in (2) and (3), reproduced as (20) and (21), and (22) and (23).

(20) $(\mathrm{aL}, \mathrm{aL}, t)$ (wh-interrogative)

Cad é a chreideann tú a cheannaigh Seán $t$ ?

what aL believe you aL bought John

'What do you believe [that John bought $t$ ]?'

(21) (aN, that, it) (wh-interrogative)

Cad é a gcreideann tú gur cheannaigh Seán é?

what aN believe you that bought John it

(22) (aL, aL, $t$ ) (relative clause)

an carr a chreideann tú a cheannaigh Seán $t$

the car aL believe you aL bought John

'the car you believe [that John bought $t$ ]'

(23) (aN, that, it) (relative clause)

an carr a gcreideann tú gur cheannaigh Seán é

the car aN believe you that bought John it

However, the mar 'as' construction shows that it is not always the case. This suggests that there should be an agreement relationship between the head of the chain pattern and the element that the chain pattern is dependent on, such as mar 'as' in the mar 'as' construction. If this is true, it suggests that hypothesis (24) should hold.

(24) In the mar 'as' construction, mar should have a feature that is compatible with a feature on $a L$, not on $a N$.

On the other hand, in $w h$-interrogatives and relative clauses, the $w h$-phrase 
and the head noun have a feature that is compatible with a feature on $a L$ and a different feature on $a N$.

Second, if the above-mentioned agreement does take place, it implies that there should be a head that triggers agreement with the COMP aL. Rizzi (1997) investigates the structure of the left periphery, that is, the complementizer (C) system, and argues that the C layer is not simply identified with a single $\mathrm{X}$-bar projection (CP), but may host topics and various operator-like elements, proposing the articulated structure for the $\mathrm{C}$ system in (25).

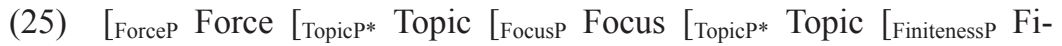
niteness [IP ...

With this in mind, let us reconsider (10), for example, reproduced as (26).

(26) $(\mathrm{aL}, t)$

Is duine deas í, mar atá a fhios agat $t$.

COP person nice her as aL+is its knowledge at-you

'She is a nice person, as you know.'

Given McCloskey's (2002) claim, the SPEC of $a L$ contains a null resumptive pronoun as a result of movement. Then, the relevant structure in (26) is (27).

(27) $\operatorname{mar}[$ cP pro $a L[$ IP $\ldots t . .]$.

If the COMP $a L$ in (27) belongs to category Force in (25), (27) will be revised to (28).

(28) $\operatorname{mar}[$ FP pro $a L[\mathrm{XP} \ldots$

In (28), the SPEC of $a L$ is occupied by the null resumptive pronoun. Therefore, mar 'as' cannot be placed in FP SPEC. Also, it cannot be a head that heads the FP in (28), which has been occupied by $a L$.

The question then arises as to where the element mar 'as' is placed in the clausal structure in (28). There are four possibilities regarding the position of mar 'as' in (28). First, it is adjoined to FP. Second, it is adjoined to the null resumptive pronoun. Third, it is the head of a phrase that takes FP as its complement. Fourth, and finally, it is in the SPEC of the head that takes FP as its complement. The first two possibilities would be rejected, since Irish does not allow two elements to be in FP SPEC. Consider the examples in (29).
a. Cé a cheannaigh cad é? who aL bought what
'Who bought what?'
b. *Cé cad é a cheannaigh $t$ ? who what aL bought 
'Who bought what?'

(29a) is grammatical in Irish, which indicates that Irish allows multiple wh-phrases in a sentence. On the other hand, (29b) is ungrammatical in Irish, which indicates (i) that a second $w h$-phrase cannot be adjoined to FP SPEC, and (ii) that FP SPEC would not be able to host more than one element. Given (i) and (ii), the first two possibilities would be rejected.

Let us then turn to the third and fourth possibilities. In the third possibility, mar 'as' is the head of a phrase that takes FP as its complement, and in the fourth possibility, it is in the SPEC of the head that takes FP as its complement. At the present stage of our understanding, it would be impossible to determine which possibility is correct. However, one common feature between the two possibilities is the fact that in each particular case, there is a new head that takes FP as its complement, and this head has a feature that is compatible with a feature on $a L$, not on $a N .^{12}$ We tentatively call this head Mar. Then, the structure in (25) is modified to the one in (30).

(30) [MarP Mar [ForceP Force [TopicP* Topic [FocusP Focus [TopicP* Topic [FinitenessP Finiteness [IP ...

Therefore, the present study contributes to further elaborating the fine structure of the left periphery.

\section{Conclusion}

In this paper, we investigated the chain properties of the mar 'as' construction, and showed that it only allowed the chain patterns headed by the COMP $a L$, such as $(\mathrm{aL}, t)$ and $(\mathrm{aL}, \mathrm{aL}, t)$. Then, we argued that this fact would suggest (i) that there should be an agreement relationship between the head of the chain pattern and the element that the chain pattern is dependent on, and (ii) that given (i), there should exist an independent head above $\mathrm{C}$.

\section{REFERENCES}

Chung, Sandra and James McCloskey (1987) "Government, Barriers, and Small Clauses in Modern Irish," Linguistic Inquiry 18, 173-237.

Maki, Hideki and Dónall P. Ó Baoill (2007) "The Modern Irish (aN, aL, $t$ ) Chain,"

12 Note that this is so, even if mar 'as' is in the SPEC of Mar, because through SPEChead agreement, the null head should bear the relevant feature. 
English Linguistics 24, 67-77.

McCloskey, James (1979) Transformational Syntax and Model Theoretic Semantics, Reidel, Dordrecht.

McCloskey, James (1985) "The Modern Irish Double Relative and Syntactic Binding," Ériu 36, 45-84.

McCloskey, James (2002) "Resumption, Successive Cyclicity, and the Locality of Operations," Derivation and Explanation in the Minimalist Program, ed. by Samuel David Epstein and T. Daniel Seely, 184-226, Blackwell, Malden, MA.

Rizzi, Luigi (1997) "The Fine Structure of the Left Periphery," Elements of Grammar: Handbook of Generative Syntax, ed. by Liliane M. Haegeman, 281-338, Kluwer, Dordrecht.

[received November 10 2008, accepted July 18 2009]

(Dónall P. Ó Baoill)

School of Languages, Literatures and Performing Arts

Queen's University Belfast

University Road, Belfast, BT7 1NN, Northern Ireland, U.K.

e-mail: d.obaoill@queens-belfast.ac.uk

(Hideki Maki)

Faculty of Regional Studies

Gifu University

1-1 Yanagido, Gifu 501-1193

e-mail: makijp@gifu-u.ac.jp 